\title{
Tessellating 'Honeycombs'
}

\author{
A. F. I. Bajunid, M. Y. Abbas \& A. H. Nawawi \\ Centre for Environment-Behaviour Studies ( $c E-B s)$, \\ Faculty of Architecture, Planning \& Surveying, \\ Universiti Teknologi MARA (UiTM), Shah Alam, Malaysia
}

\begin{abstract}
'Tessellation planning', an accidental innovation initiated by a local architect in Malaysia, fundamentally challenges rectilinear organisations of mass housing layouts which has mainly dominated the Malaysian mass housing landscape. This creative 2-dimensional tessellating method is merely a way of subdividing land into small triangles and interweaving hexagons. It is very much similar in theory to tessellating a surface with different varieties of patterned tiles to generate complex and unique patterns. These patterns resonates forms of Islamic Art, but rather than just mere colours, it is decoded into physical constructs of houses, gardens, parks and roads. Six 'tiles' unite to form a hexagon shaped 'neighbourhood cul-de-sac', containing a cluster of houses surrounding a small communal park. The collective 'tessellation of honeycombs', efficiently interlocks with one another, producing semi-pedestrian networks of a small township rendering synergistic harmony with nature. This paper aims at expressing that inspiring thought processes by identifying its artistic precedents; in bio-mimicking nature as well as its historical prototypes. These literature findings shall establish its quintessence. It is desired that the crux of this knowledge shall provide a design alternative to a much needed sustainable framework of affordable mass housing planning, towards cultivating and raising the quality of life in Malaysia.

Keywords: tessellation planning, affordable honeycomb housing, cul-de-sac, neighbourhoods, Malaysia.
\end{abstract}

\section{Introduction}

Tessellation planning and its historical precedents have only been recently explored, rationalising the undertakings of architect Mazlin Ghazali in his 
relentless endeavours in challenging the common norms of mass terrace layout arrangements in Malaysia. The Author's continuous initiative in archiving on the matter of tessellation planning has spanned over six years. Among accounts of critical intellectual discussions was with various Consultants; Architects, Planners, Quantity Surveyors, Engineers, and Clients; Developers, Individuals, Scholars and Academics alongside close feedback of Governmental bodies and local Authorities. The end users has also been engaged to better understand the perceptions and needs of the mass public, shedding light to the actual circumstances and requirements in the Malaysian context. Numerous informal interviews and statistical analysis were conducted by Universiti Putra Malaysia and published in separate accounts, documenting supporting evidence.

In order to remain unbiased to the facts at hand, this paper only strives to evaluate 2-dimensional tessellation planning and its currently known precedents to justify its accuracy with supporting documents already in general circulation. Upon defining its broad concepts, this paper first attempt to draw upon the origin and sources of ideas related to the 2-dimensional tessellation concepts, particularly from exemplary and inspirational works of the $20^{\text {th }}$ century great masters. Then, the paper further analyses initial developments of tessellation planning by architect Mazlin Ghazali and retired visiting scientist Mohd Peter Davis.

\section{Concepts}

\subsection{Thermal comfort Honeycomb housing}

Thermal Comfort Honeycomb Housing aims at the provision of an environment equivalent to that of the cul-de-sacs, but at a more affordable scenario. According to a study conducted by Eran Ben-Joseph in America in 1995 (Southworth and Ben-Joseph [1]), discovered that the cul-de-sacs were highly preferred to that of the 'grids' and 'loops'.

Within the Malaysian setting, a residential property in a cul-de-sac would prove to be vastly exorbitant. $80 \%$ of families in Malaysia would not be able to afford anything more than RM150k (Davis and Nordin [2]). Affordable quality housing, a constant issue with the projected population increase, Davis et al. [3], poses multiple challenges for the Malaysian Government. In turn, laws and regulative initiatives to deliver the immediate demands of affordable housing create a surplus of poor terrace housing designs and barrack-like communities. This has, during Malaysia's booming years supersedes its primary function in creating affordable quality housing.

\subsection{Honeycomb housing}

Mazlin Ghazali in collaboration with Mohd Peter Davis has over the past ten years researched and conducted practical applications of the innovative housing concept. It is essential to note that Ghazali began his practice initially orientating along the construction of low-cost and affordable housing. His experiences in 
constructing more than 10,000 units, Ghazali [4], of these affordable housing, has inspired him to question the norms of linear planning and the barracks-like layout. He has among many occasions challenged that the 'quality of life' should not be compromised in low-cost communities. His determined endeavours led him indirectly, to the cul-de-sac. While resolute in finding a better social environment, he was particularly concerned on the efficiencies of infrastructure, construction costs and density, which was a prerequisite to mass housing. As he continued in his exploration of cul-de-sac communities, the notion of subdividing land plots more efficiently, or tessellation planning was stumbled upon by mere accident,

Ghazali briefly elaborates the tessellation planning concept in Figure 1 (Tessellar [5]).
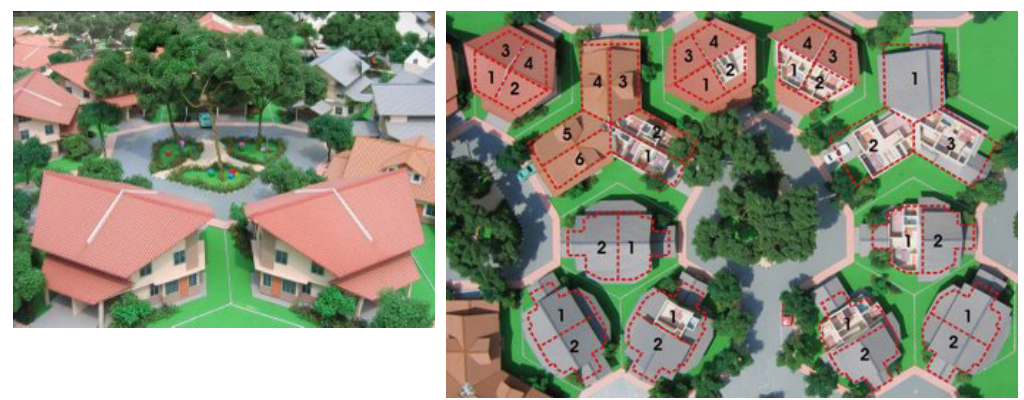

Figure 1: A perspective (left) and plan of a Honeycomb layout. (Source: Tessellar [5]).

"First, we improve the cul-de-sac by making it bigger to be able to fit in a public green area in the middle because local planning regulations require $10 \%$ of any residential development to be open space. Then we create an interlocking arrangement of cul-de-sacs such that each building lot would face at least two cul-de-sacs. ... In Honeycomb housing, we sub-divide the buildings into 2, 3, 4 or 6, to create duplex, triplex, quadruplex or sextuplex units. As we divide the buildings, the land area and the built-up area become smaller; the number of units in the layout and the density of the development go up. ... All these make the housing units less expensive. Yet every building still retains a public access. Furthermore, the quality of the external environment is not compromised-only that more units share it!"

It is a unique approach intensely vital in confronting the sociological stigma of low to medium cost dwellings. Ghazali continues in his endeavours in stating that there are basically two capacities to the Honeycomb Housing Layout. First, is the designing method of which is based on the geometric concept of tessellations; second, is the identification and interpretation of the idea of a 'neighbourhood unit', which was made known by Clarence Perry in 1929 (Johnson [6]).

In closer detail, the Honeycomb structure and reasoning is unique and commercially viable but is rather, a sequential development of processes and 
ideas, or rather - purely accidental. Nevertheless, it was a discovery that predates back to the ancient Greeks.

\subsection{2-Dimensional tessellations}

The word geometry when defined by the Oxford Dictionary comes from the Greek word 'Geometria' which essentially means 'earth measurement'. According to Martin Gardner (a renowned recreational mathematician), the ancient Greeks have identified and proven that there are just three regular polygons to tile the plane; the equilateral triangle, the square and the regular hexagons (Figure 2). In his series of Mathematical Games, Gardner [7], defines tessellation as "an infinite supply of jigsaw puzzle pieces which if it is possible, to cover or tile the entire plane, would result in a pattern called tessellation. This is seen throughout the world for floor and wall coverings and as patterns for tapestries, rugs, quilts, furniture, clothing and other objects."
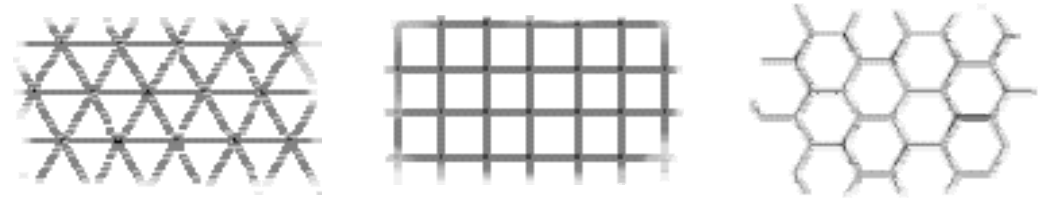

Figure 2: Three regular polygons to tile the plane. (Source: Redrawn by Author).

One such example of an artist who indulged in tessellation is M. C. Escher. Escher elaborately tessellates the plane with intricate shapes of animals and other living creatures (Figure 3).
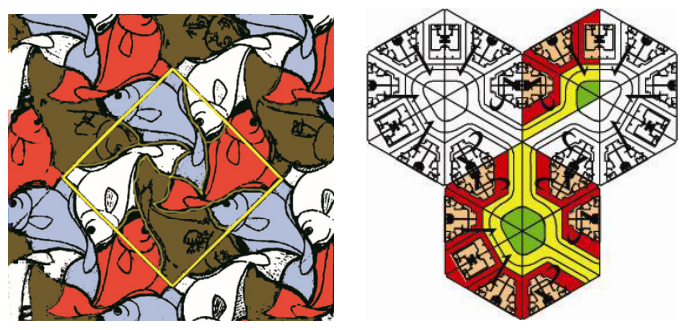

Figure: 3 (left) and 4 (right): (Left) a sample work of Escher. (Source: Davis et al. [3]). (Right) Honeycomb 'tiles'. (Source: Tessellar [5]).

It would be extremely easy to artistically portray the tessellation method as only a form and deviation of art and by far a means of designing towns and cities. We have, however, to ponder, when do art and science converge?

Ghazali explains (in Figure 4) "...that in mathematics, to tessellate means to cover a plane with a pattern without gaps or overlap. For centuries artists and 
craftsmen have used tessellation as a tool to create visual effects on surfaces. Tiling is the most common form of tessellation. ... In Honeycomb housing, we apply this creative mathematical technique to town planning, where the colours are not merely decorative but represent functional space." (Tessellar [5]).

It is fascinating to learn that in Gardner's findings, he too mentions that, " $A$ tile that tessellates obviously can have an infinite variety of shapes, but by imposing severe restrictions on the shape and task of classifying and enumerating, tessellations is reduced to something manageable." (Gardner [7]).

Thus it is observed that the simple tessellation technique of Honeycomb is actually providing a more efficient way of planning land-use. An example of a simple tessellation or 'efficient packing' as described by Loeb [8], is to consider a number of identical circular disks on a table top. When these disks are arrayed in a square, $79 \%$ of the total area of the table top is covered by the disks, while $21 \%$ is left exposed (Figure 5). However, if triangularly arrayed, as when Ghazali vividly illustrates in his approach to the Honeycomb's efficiency, (Figures 6 and 7, Davis et al. [3]), 91\% is covered by the disks while 9\% is left exposed.
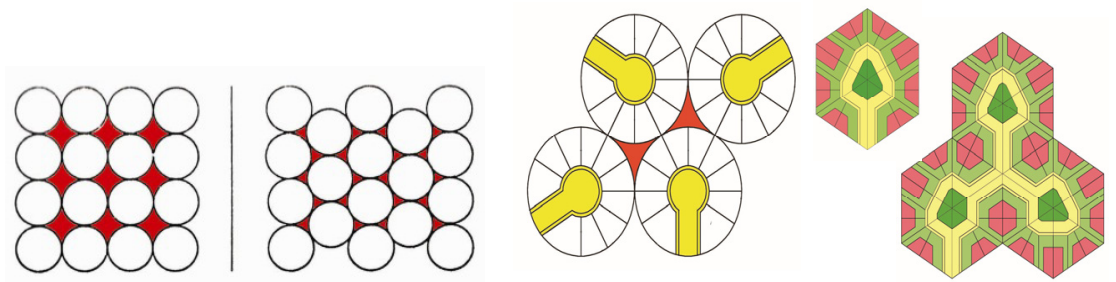

Figure: $\quad 5,6$ (left) and 7 (right): (Left) Circles arrayed in a square and circles arrayed triangularly. (Right) The circle arrayed triangularly is more efficient than arrayed in a square, but nonetheless still creates gaps as compared to the hexagon as they tessellate fully. (Source: Davis et al. [3]).

\subsection{The geometrics of the Honeycomb}

It is also noted that the geometrics of tessellations are not even foreign to Nature itself, as was recorded by Loeb in his analysis, "The geometrics of close packing produce interesting physical patterns. Imagine a group of bees, each constructing a cylinder of wax around himself. If each bee produces a cylinder with the same radius, then the most efficient use of space will be made if the bees locate themselves in a triangular array.... Since the wax is soft, the cylinders will, from here on flow together to form the familiar hexagonal honeycomb pattern. That this pattern, the result of a simple biological growth law, is generally considered attractive... ", Loeb [8] (Figure 8).

\subsubsection{Alhambra, Spain}

It is imperative that precedents to such creative and practical union of science and art are studied. Upon preliminary studies, it was first apparent that the 
tessellation techniques were found mainly on tiles, as even the distinctive artist, Escher, observed that, "The Moors were masters in the filling of surface with congruent figures and left no gaps over. In Alhambra in Spain, especially, they decorated the walls by placing congruent multicolored pieces of majolica together without interstices.", Gardner [7], (Figure 9).
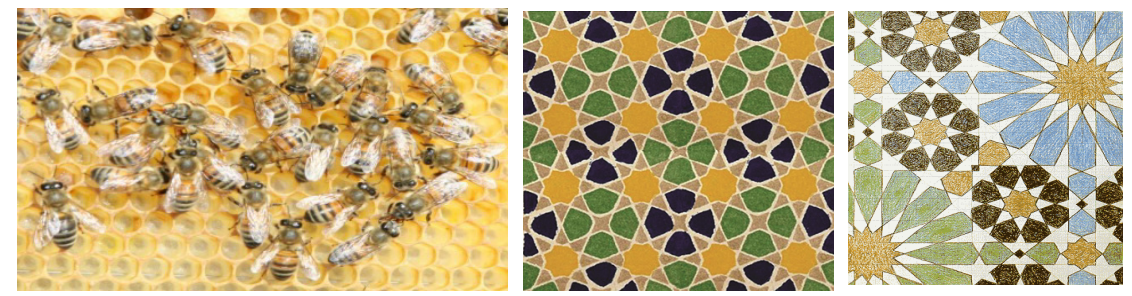

Figure: $\quad 8$ (left) and 9 (right): (Left) a Honeycomb. (Source: Google Pictures). (Right) A Moorish, Islamic pattern (Source: Davis et al. [3]) and Escher's sketch of a tile in Alhambra in 1936. (Source: Google Pictures).

\subsubsection{Nature}

Research insights reveal that many building forms and spaces have in fact been practised and created by simple tessellation. Leone Battista Alberti [9] (of Florence, in 1485) in his On the Art of Building in Ten Books, describes his ideal plan forms of temples as; "It is a manifest that Nature delights principally in round figures, since we find that most things which are generated, made or directed by Nature are round... We find too that Nature is sometimes delighted with figures of six sides; for bees, hornets, and all other kinds of wasps have learnt that no other figure for building cells in their hives, but the hexagon... The polygons used by the Ancients were either of six, eight or sometimes ten sides."

\section{Inspirational historical works of 2-dimenional tessellations}

\subsection{Frank Lloyd Wright on individual buildings}

It is illuminating to learn that the great master builder Frank Lloyd Wright explored such forms and techniques in his works as well. The Suntop Homes near Philadelphia (Figure 10), the apartment buildings of Bouwerie, New York (Figure 11), the Greek Orthodox Church in Madison (Figure 12) and Huntingdon Hartford (Figure 13), were all developments of the symmetrical tessellation process of forms translated into plans and the urban fabric. This is clearly defined as part of the 'point groups' in the tessellation family (Park [10]).

\subsection{Le Corbusier on symmetries of mass housing}

Another renowned master builder, Le Corbusier in his grandest urban scheme of the development of the left bank of the Schelde at Antwerp (Figure 14), delved 


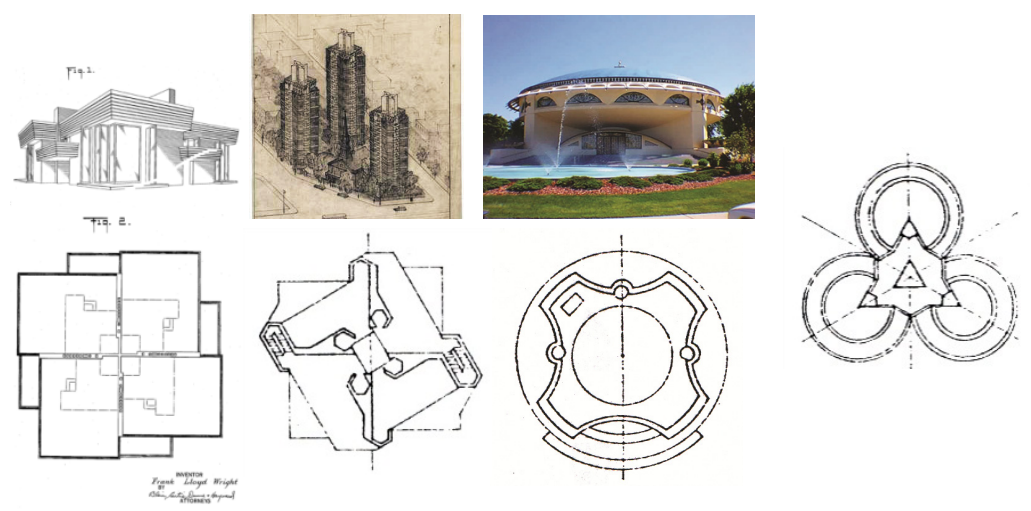

Figure: 10 (left), 11 (centre) and 12 (right) 13 (extreme right): (Left) Suntop Homes, 1939. The "Ardmore experiment". The structure included four housing units in Ardmore, Pennsylvania. Four of the units were to be built, but only one was ever constructed. (Source: Adapted from Google Pictures). (Centre) St Mark's Tower. 1939 (Source: Above, www.moma.org, Below, adapted from Google Pictures). (Right) Greek Orthodox Temple (Source: Above, www.moma.org, Below, adapted from Google Pictures). (Extreme right) Huntingdon Hartford Clubhouse (Source: Adapted from Google Pictures).

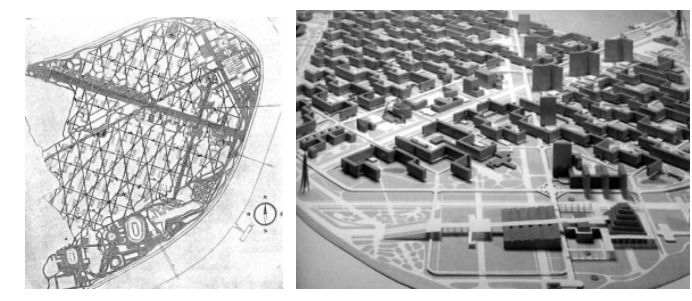

Figure 14: Le Corbusier's symmetries of tessellations proposal in 1933 (Source: www.ethesis.net).

into processes of symmetries of tessellations. This in particular, belongs to the 'frieze group' symmetries (Mirman [11]), where mass housing with identical units assembled into apartment buildings, terraces and other arrangements which was planned, such as the terraced row housing at Pessac, Paris (Figure 15).

Le Corbusier in La Ville Radiuse (Figure 16) consists of masterplans of symmetry groups divided into blocks of different functions such as the manufacturing (ateliers), residential (la ville verte) and apartments (unité d'habitation) and the business districts. It is consistent that the masterplans are based on a square grid of $400 \mathrm{~m} \times 400 \mathrm{~m}$ which keeps the autostrades on the periphery of the development, in proposing a large traffic-free park within. Le Corbusier also introduced six combinations of tessellations within this 


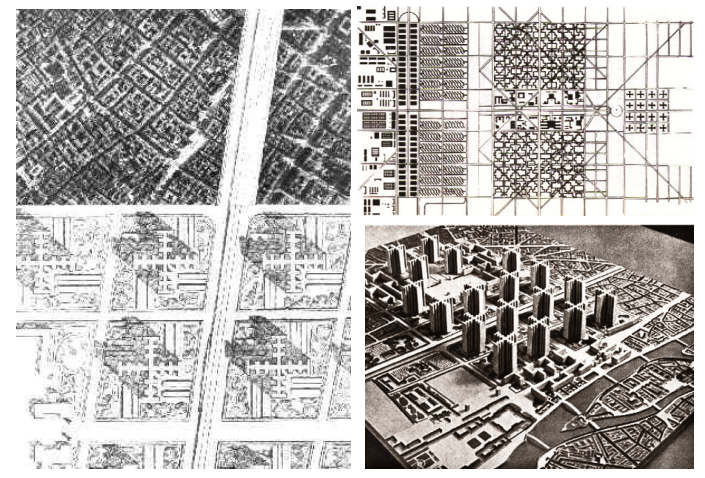

Figure: 15 (left) and 16 (right): (Left) a proposed housing development for Paris in architecture, the expression of the materials and methods of our times by Le Corbusier, architectural record, August 1929. (Source: www.home.vicnet.net.au). (Right) La Ville Radiuse. (Source: www.tu.harburg.de).

masterplan, which derived from a single architectural motif - which was mixed in the final composition.

\section{3 'Quadruple block plan'}

Ironically, no precedents came ever so close to tessellating smaller residential units as to Wrights proposal of a development in a quarter-section (quarter mile) of Chicago (Figure 17). Wright in his development of the residential units based it on the principle of the 'quadruple block plan'. He states, “... Each householder is automatically protected from every other householder. He is the only individual upon the entire side of his block. His utilities are grouped to the rear with his neighbours utilities and his yard, front or rear, is privately his own.
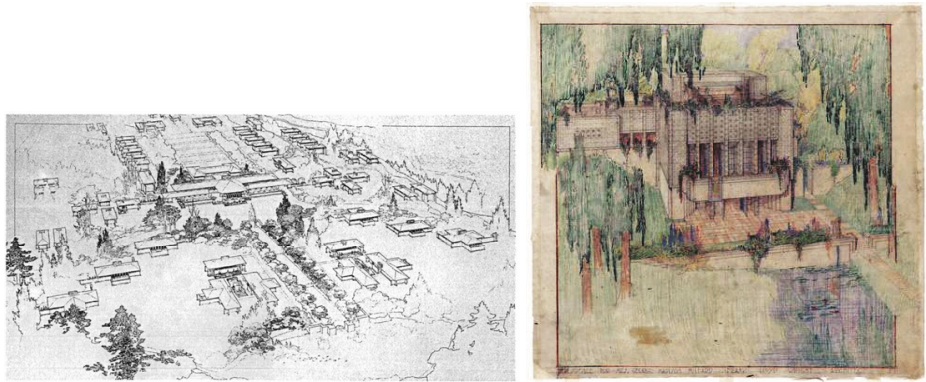

Figure: 17 (left) and 18 (right): (Left) Coma Orchard, c. 1909. Arial perspective. From Ausgefurre Bauren und Entwurfe Von Frank Lloyd Wright, 1910. (Source: http://repository.upenn.edu/arch papers/3). (Right) Frank Lloyd Wright's perspective of La Miniatura. (Source: www. americancorner.org.tw). 
His windows all look upon open vistas and upon no one's unsightly necessities. His building is in unconscious but necessary grouping with three of his neighbours, looking out upon harmonious groups of other neighbours, no two of which would present to him the same elevation even were they all cast the same mould. A succession of buildings of any given length by this arrangement presents the aspect of well-grouped buildings in a park, of greater picturesque variety than is possible where façade follows façade”, Gill [12].

As Wright attempts further with 'quadruple block' planning with a development containing clusters of four houses in La Miniatura, (Figure 18), however which was still limited by arranging blocks, lined symmetrically.

\section{Recent 2-dimensional tessellation planning in resemblance}

\section{1 'Neighbourhood unit'}

Ghazali's identification of the 'neighbourhood unit' is in fact, synonymous to the 'quadruple block plan' by Frank Lloyd Wright. Ghazali meticulously explicate the manner that a neighbourhood is formed, by predominately going through the process of laying the 'neighbourhood tiles', detailed below are some of his excerpts:-

\subsection{1 'Courtyard neighbourhood'}

"First, the layout of a single cluster of houses is placed on a hexagonal 'tile'. This is a small community of about 16 houses for example. Note that all the houses face the common garden in the middle of a looping road. There is a clear boundary which is the party wall and fence that runs across the back of the houses. There is however, only one road leading into this cluster. Because the area in the middle of the houses forms a sort of courtyard, we call this arrangement a 'courtyard neighbourhood'. The courtyard is only about 150 feet wide. Within this distance, someone standing at his front garden would be able to identify the facial features of other people outside. With a population of about 80 persons (based on 5 persons per unit), it is possible for a resident to at least recognize most of his neighbours. He would likely to know when a stranger strays into this intimate setting. " (Figure 19), Tessellar [5].

\subsection{2 'Cul-de-sac neighbourhood'}

The second step is when three almost identical tiles are combined together. There are 36 houses in a 'cul-de-sac neighbourhood' with a population of about 180 persons. This is a bigger neighbourhood, less intimate, less focused, but still defined by a single entry. The population of this area is not much higher than "the figure 150 (that) seems to represent the expected maximum number of individuals with whom we can have a genuine social relationship, the kind that of relationship that goes with knowing who they are and how they relate to us... it's the number of people you would not feel embarrassed about joining uninvited for a drink if you happened to bump into them in a bar', Dunbar [13], (Figure 20). 

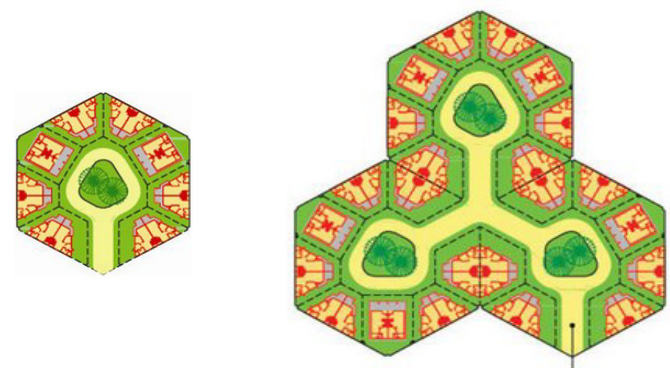

Figure: 19 (Left) and 20 (Right): (Left) 'Courtyard Neighbourhood'. (Right) 'Cul-de-sac Neighbourhood' (Source: Tessellar [5]).

These hexagonal tiles can be tiled further to create a 'block neighbourhood' of about 15 acres. There are about 250 houses bounded by a distribution road. At the edges are some courtyard tiles - cul-de-sacs courtyards dissected into two. A central park for older children is provided in the middle of the block, allowing for footpaths to run from one cul-de-sac to another. The population here would constitute to about 1250 persons. (Figure 21).
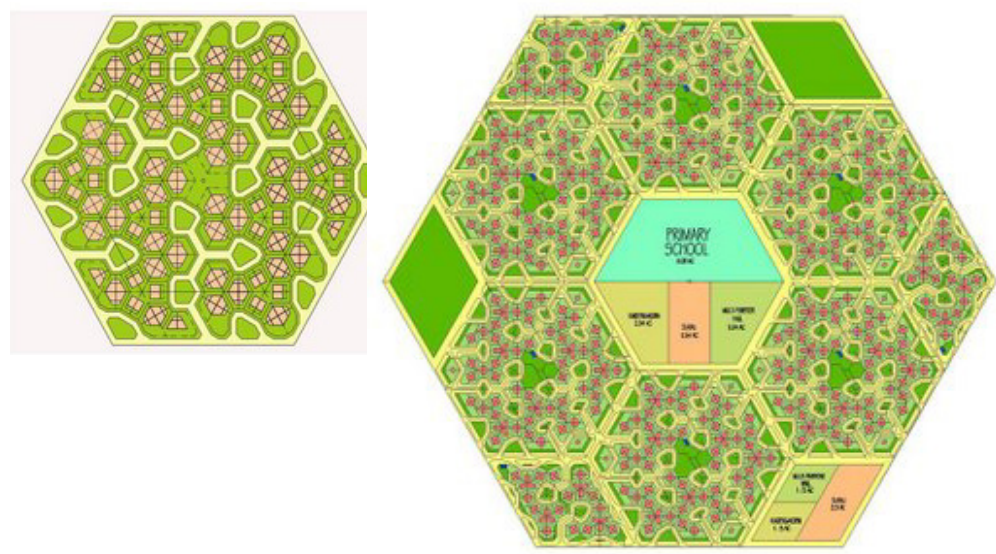

Figure: 21 and 22 (Left) 'Block Neighbourhood'. (Right) Honeycomb Township (Source: Tessellar [5]).

\subsection{3 'Honeycomb townships'}

A bigger community, equivalent to seven 'block neighbourhoods', is created to form a 'Honeycomb Township'. The residential areas are arrayed around a central area that comprises a primary school and other communal township amenities. The number of houses is around 1750 units, with about 8750 persons. Ironically, this is the community size that accords with the term "neighbourhood unit" that is normally used by planners in Malaysia (Figure 22). 


\section{Conclusion}

\subsection{Community}

The Honeycomb tessellating approach adopts a hierarchical concept of community; from the smallest residential family unit type to the largest neighbourhood township, of logical proportions to its inhabitants. Greenery and open space is equally distributed from the singular cell of a courtyard to the public amenities of an entire community. Currently, tessellation planning is a planning process at its infancy, and major design and planning findings are still being discovered as the development of tessellation in 2-dimensional architectural planes is further explored.

It is baffling to have been able to identify two great Architects in an attempt to further scrutinize the preference to 2-dimensional tessellations. This reservation is manifested by Escher in his arts as he asks, "I often wondered at my own mania for making periodic drawings... What can be the reason of my being alone in this field? Why does none of my fellow-artists seem to be fascinated as I am by these interlocking shapes?', Gardner [7]. It is his thoughts that may have lingered with Frank Lloyd Wright and Le Corbusier and now with Mazlin Ghazali.

\subsection{Tessellation planning}

In this paper, it is learnt that there lay still many unexplored opportunities on the reinvention of the fundamental hypothesis of a city. Tessellation planning's possibilities are infinite, and the potential for development are merely scratching the surface of technological sciences and arts. It is evident that research be pursued, in fulfillment in its form of intellectual continuity from the great Architects of the past in testing the norm and technology of the times to solving the prolonged issues of quality and affordability of mass housing. It is an articulate tool of town planning, from the macrocosm of the family unit to the vast city as an entity. Would it be due time that we Malaysians acknowledge our housing issues and address it with the many tools made available to us?

It has been made clear that the two greatest architects of the twentieth century - Frank Lloyd Wright and Le Corbusier were able to innovate due to their deep understanding of symmetry and pattern structure. It is here that the Author wishes to ponder on the words of Owen Jones's [14] that, “...the principles discoverable in the works of the past belong to us, not so the result. It is taking the end for the means. No improvement can take place in the Art of the present generation until all classes, artists, manufacturers and the public are better educated in Art and the existence of general principles is more fully recognized... If a student in the arts, earnest in his search after knowledge, will only lay aside all temptation to indolence, will examine for himself the arts of the pasts, compare them with the works of Nature, bend his mind to a thorough appreciation of the principles which reign in each, he cannot fail to be a creator, and to individualize new forms." 


\section{Acknowledgements}

The authors would like to acknowledge an earlier adaptation of this paper that was previously published in the conference proceedings of World Housing Congress 2007 on Affordable Quality Housing, held in Terengganu, Malaysia. The authors wish to express extreme gratitude to all industry collaborators and academic supervisors who continuously contributed to the thought processes for the formulation of this extended condensed paper. This paper was also made possible by the Fundamental Research Grant Scheme provided by the Ministry of Higher Education, Malaysia and Universiti Teknologi MARA Malaysia.

\section{References}

[1] Southworth, M. \& Ben-Joseph, E. Street Standards and The Shaping of Surburbia. Journal of The American Planning Association, Vol. 61, 65-81, 1995.

[2] Davis, M. P. \& Nordin, N. A. Assessing Affordability of Housing. New Straits Times, Property Times, Viewpoint, Saturday, May 1, p. 8, 2004.

[3] Davis, M. P., Nordin, N. A. \& Ghazali, M. Thermal Comfort Honeycomb Housing: An Alternative to Terrace Housing. Universiti Putra Malaysia (UPM), UPM Press, 2006.

[4] Arkitek M. Ghazali, http://arkitekmghazali.blogspot.com.

[5] Tessellar > Introduction, www.tessellar.blogspot.com.

[6] Johnson, D. L. Origin of the Neighbourhood Unit. Planning Perspectives, Vol.17, 227-245, 2002.

[7] Gardner, M. Martin Gardner's Mathematical Games. Cdr Edition. ed. USA, American Association of America, 2005.

[8] Loeb, A. L., The Architecture of Crystals. IN Kepes, G. (Ed.) Modules, Proportions, Symmetry, Rythm Vision and Value Series. New York, George Braziller, 1966.

[9] Alberti, L. B., On the Art of Building in Ten Books, Boston, MIT Press, 1988.

[10] Park, J.-H., Analysis \& Synthesis in Architectural Designs: A Study in Symmetry. Nexus Network Journal, Vol 3, 2001.

[11] Mirman, R., Point Groups, Space Groups, Crystals \& Molecules, London, World Scientific, 1999.

[12] Gill, B., Many Masks: A Life of Frank Lloyd Wright, De Capa Press, 1998.

[13] Dunbar, R., Grooming, Gossip and the Evolution of Language, London, Faber \& Faber, 1996.

[14] Jones, O. The Grammar of Ornaments: A Unique Collection of Over 2350 Classic Patterns, London, Dorling Kindersley, 2001. 